\title{
Isolated unilateral palatal and vocal cord palsy as an initial presentation of chronic inflammatory demyelinating polyradiculoneuropathy
}

Madhavi Karri* id and Balakrishnan Ramasamy

\begin{abstract}
Introduction: Chronic inflammatory demyelinating polyradiculoneuropathy (CIDP) is an acquired autoimmune disease of the peripheral nervous system. Its clinical presentation and excellent response to steroids is a hallmark to the disease entity. It is usually a straight forward diagnosis in typical cases. Atypical CIDP often is of diagnostic concern and has been a challenge for practising neurologists.

Case description: Here, we present a 56-year old female presented with isolated left palatal palsy preceded by a short febrile illness. Clinically consistent with post-infectious bulbar palsy, she was treated with intravenous pulse steroids and antibiotics. She had progressive disease and later developed quadriparesis with neck flexor weakness with progressive bulbar weakness and hypercapnic respiratory failure.

Discussion and evaluation: MRI whole spine with contrast showed nerve root enhancement. Nerve conduction studies of all four limbs and LP and CSF analysis were consistent with CIDP. She was treated with intravenous immunoglobulin $(0.4 \mathrm{~g} / \mathrm{kg}$ for five consecutive days). She showed mild improvement of symptoms initially and later had deterioration of symptoms within a week interval. She received two doses of Rituximab of 1 gram each within 3 weeks apart, after which she has gradual improvement. She was able to tolerate orally and able to walk without support following 1 month after treatment, and there were no further relapses except for the persistence of minor sensory symptoms after 6 months of follow-up.
\end{abstract}

Conclusion: Isolated cranial nerve involvement presenting as CIDP is a rare entity. Intravenous immunoglobulin and newer immunosuppressants like CD-20 monoclonal antibodies like rituximab have a significant role in the treatment.

Keywords: Chronic inflammatory demyelinating neuropathy, Nerve conduction studies, MRI, Post-infection, Rituximab

\section{Introduction}

Isolated unilateral palatal palsy is a rare clinical entity seen in adults. It usually caused by affection of the pharyngeal branch of the vagus nerve. Most possible etiological associations are infections, trauma (adenoidectomy or craniofacial trauma), tumour (meningiomas or cerebellopontine angle tumours), neuromuscular disorders (Guillain barre syndrome (GBS) or motor neuron

\footnotetext{
* Correspondence: dr.madhavikarri@gmail.com

Department of Neurology, PSG institute of Medical Sciences and Research, PSG Hospitals, Peelamedu, Coimbatore, Tamil Nadu 641004, India
}

disease or bulbar onset myasthenia gravis) and vascular (internal carotid artery aneurysm or dissection or vascular insult) disorders. Infection-related palsy is well documented, and more common organisms involved are varicella-zoster, herpes simplex virus, coxsackievirus, measles virus, poliovirus, diphtheria and enteric infection. Other infections include tuberculosis, syphilis and intracranial or retropharyngeal or retro-parotid abscess. Here, we report an isolated palatal palsy in an elderly female which later gradually progressed causing ascending quadriparesis with respiratory and bulbar weakness. 


\section{Case description}

A 56-year old female, a retired school teacher, has presented with fever and dry cough for 1 week, 2 months back following which she developed insidious onset gradually progressive bulbar weakness in the form of hoarseness of voice and dysphagia to both solids and liquids. She had a known hypertensive, diabetic and coronary artery disease for the past 6 years and was on regular medication. No history of any cognitive impairment or behavioural abnormalities were noticed. There were no diurnal variations of symptoms, no wasting or fasciculations. There was no history of any chronic neurological illness in the family, no history of diabetes mellitus, tuberculosis or any heavy metal exposure in the past.

Clinically, she was conscious, alert with MMSE of 30/ 30. She had left palatal palsy with hoarseness of voice and poor gag reflex with uvula being central. Her spinomotor system and sensory system were normal with diminished deep tendon reflexes. She had no evidence of meningeal signs. She was evaluated with a working diagnosis of isolated left palatal palsy and left vocal cord palsy. Her complete blood picture showed normal leukocyte count $\left(9000 \mathrm{~mm}^{3}\right)$ with normal haemoglobin $(12 \mathrm{~g} / \mathrm{dl})$ and platelet count $\left(365,000 \mathrm{~mm}^{3}\right)$. Her erythrocytic sedimentation rate was normal $(22 \mathrm{~mm}$ after $2 \mathrm{~h}$ ). Glycosylated haemoglobin was $7.9 \%$. Serum creatinine phosphokinase was normal. Her thyroid function tests were normal (thyroid-stimulating hormone-1.32 IU/L).

MRI brain plain with angiogram of cerebral blood vessels was normal. Contrast-enhanced CT thorax and neck showed no evidence of mass lesion/malignancy. Lumbar puncture and cerebrospinal fluid (CSF) analysis showed normal cells (4 cell with $70 \%$ lymphocytes) with mildly elevated protein $(73 \mathrm{~g} / \mathrm{dl})$ and normal glucose $(166 \mathrm{mg} /$ $\mathrm{dl}$ ) and LDH being normal (13). CSF for gram stain and cultures were negative. CSF for tuberculosis (TB-PCR) was negative. Considering as higher possibility of postinfectious isolated left bulbar palsy, she was started on intravenous pulse steroids (methylprednisolone $1 \mathrm{~g} /$ day) and supportive care. She was also given a trial of swallowing exercises with soft mashed diet. Then on the second day, she had worsening dry cough with cough syncopal episodes. She developed desaturation secondary to aspiration to both solids and liquids (even to her saliva). Chest X-ray showed para-cardiac haziness with no evidence of consolidation. She was started on empirical broad-spectrum antibiotics for the same. She had worsening bulbar symptoms and developed weakness of all four limbs with absent deep tendon reflexes and bilateral Babinski negative. Nerve conduction studies were done on 02 September 2018 (Table 1) showed sensory axonal neuropathy (considering secondary to diabetes mellitus). She has undergone percutaneous endoscopic gastrostomy because of persistent severe bulbar weakness.
After 2 weeks later (15 September 2018), she had worsening bulbar weakness with respiratory arrest. Arterial blood gas analysis showed evidence of hypercapneic respiratory failure with pCO2 of 69 . She was shifted to intensive care and put on ventilatory support. Now on re-examination, she developed new-onset neck flexion weakness with worsening quadriparesis with the power of 2/5 with absent DTR and bilateral plantar flexor. MRI whole spine plain and contrast showed enhanced nerve roots at lower dorsal and lumbar level. Repeat lumbar puncture and CSF analysis showed mildly elevated protein $(58 \mathrm{~g} / \mathrm{dl})$ with normal glucose $(122 \mathrm{mg} / \mathrm{dl})$ with normal counts (total cells-2) indicating an albumincytological dissociation. Repeat NCS of all four limbs (16 September 2018) showed reduced amplitudes with increased motor latencies and absent $\mathrm{F}$ waves-suggestive of sensorimotor axonal polyradiculoneuropathy (Table 1).

With the above findings favouring evidence of chronic inflammatory demyelinating polyradiculoneuropathy, she was started on intravenous immunoglobulin $(0.4 \mathrm{~g} / \mathrm{kg} /$ day for five consecutive days). She had undergone tracheostomy for bulbar weakness and need for prolonged ventilatory requirements. She had a mild improvement in weakness initially after IVIg. Five days later, she had a worsening weakness with wasting of small muscles of hand. Repeat blood parameters showed normal metabolic profile with no evidence of infection or electrolytes abnormality. She was planned for rituximab because of active disease process with worsening symptoms even after receiving full dose of IVIg. She received two doses of rituximab within 3 weeks apart. After first dose of rituximab (1000 $\mathrm{mg}$ given on 5 October 2018), her bulbar symptoms improved and was able to take orally well. She received the second dose of rituximab of $1 \mathrm{~g}$ on 20 October 2018. After receiving two doses of rituximab along with rehabilitative care, her weakness gradually improved and was able to walk with one-person support at the time of discharge. She was able to take orally well and can able to walk without assistance following 1 month after treatment and no relapses except for persistence of minor sensory symptoms after 6 months of follow-up.

\section{Discussion and evaluation}

CIDP is an acquired disease of the peripheral nerve destroying peripheral myelin. It presents as chronic progressive, stepwise progressive or relapsing weakness developing over at least 2 months or more with absent reflexes (areflexia) [1]. It is coupled with nerve conduction findings showing evidence of demyelination, essentially defining the illness [2]. In advanced and long-standing cases, axonal changes are noted due to denervation of nerve fibres. CSF analysis shows cytological-albumin dissociation. Nerve biopsy reports show interstitial and perivascular 
Table 1 Nerve conduction studies (NCS)

\begin{tabular}{|c|c|c|c|c|c|c|}
\hline \multicolumn{4}{|c|}{ NCS 02 September 2018} & \multicolumn{3}{|c|}{ NCS 16 September 2018} \\
\hline \multicolumn{7}{|c|}{ Motor nerve conduction study } \\
\hline Nerve & Latency (ms) & Amplitude (mV) & $\mathrm{CV}(\mathrm{m} / \mathrm{s})$ & Latency (ms) & Amplitude (mV) & $\mathrm{CV}(\mathrm{m} / \mathrm{s})$ \\
\hline \multicolumn{7}{|l|}{ Left median } \\
\hline Wrist & 5.3 & 2.2 & 48.3 & NR & NR & NR \\
\hline Elbow & 9.7 & 2.1 & & & & \\
\hline \multicolumn{7}{|l|}{ Right median } \\
\hline Wrist & NR & NR & NR & NR & NR & NR \\
\hline \multicolumn{7}{|l|}{ Elbow } \\
\hline \multicolumn{7}{|l|}{ Left ulnar } \\
\hline Wrist & 3.7 & 5.6 & 41.9 & 4.3 & 0.3 & NR \\
\hline Below elbow & 8.9 & 5.5 & & NR & NR & \\
\hline \multicolumn{7}{|l|}{ Right ulnar } \\
\hline Wrist & 4.6 & 4.0 & 46 & 5.3 & 1.0 & 44 \\
\hline Below elbow & 9.6 & 3.9 & & 10.4 & 0.5 & \\
\hline \multicolumn{7}{|l|}{ Left peroneal } \\
\hline Ankle & 4.2 & 7 & 41.4 & 6.3 & 1.0 & 40.2 \\
\hline Head of fibula & 14.2 & 5.3 & & 14.8 & 0.5 & \\
\hline \multicolumn{7}{|l|}{ Right peroneal } \\
\hline Ankle & 4.3 & 3.6 & 33.3 & 6.9 & 0.7 & NR \\
\hline Head of fibula & 16.2 & 1.7 & & NR & NR & \\
\hline \multicolumn{7}{|l|}{ Left tibial } \\
\hline Ankle & 3.9 & 15.1 & 33.5 & 8.5 & 0.7 & 40.2 \\
\hline Popliteal fossa & 16.6 & 6.9 & & 17.4 & NR & \\
\hline \multicolumn{7}{|l|}{ Right tibial } \\
\hline Ankle & 4.4 & 10.4 & 33.9 & 7.6 & 0.5 & 33.5 \\
\hline Popliteal fossa & 16.6 & 5.1 & & 18.1 & 0.5 & \\
\hline F waves & Latency (ms) & & & Latency (ms) & & \\
\hline Left median & 37.5 & & & NR & & \\
\hline Right median & NR & & & NR & & \\
\hline Left ulnar & 33.3 & & & 46.4 & & \\
\hline Right ulnar & 33.5 & & & NR & & \\
\hline Left peroneal & 53.1 & & & 56.9 & & \\
\hline Right peroneal & 52.3 & & & 61.0 & & \\
\hline Left tibial & 59.0 & & & 66.6 & & \\
\hline Right tibial & 60.0 & & & 69.7 & & \\
\hline \multicolumn{7}{|c|}{ Sensory nerve conduction study } \\
\hline Sensory nerves & Peak latency & Amplitude (mV) & $C V$ & Peak latency & Amplitude (mV) & $\mathrm{CV}$ \\
\hline Right median & NR & NR & NR & NR & NR & NR \\
\hline Left median & 2.4 & 6.7 & 58.8 & NR & NR & NR \\
\hline Right ulnar & 3.8 & 5.8 & 32.6 & NR & NR & NR \\
\hline Left ulnar & 2.5 & 7.3 & 48.4 & NR & NR & NR \\
\hline Right sural & 2.3 & 6.0 & 53.9 & NR & NR & NR \\
\hline Left sural & 2.4 & 6.1 & 59.4 & NR & NR & NR \\
\hline
\end{tabular}

NCS 1: The motor nerve conduction studies show normal distal latency with normal CMAP amplitude distally in both ulnar and tibial. There are prolonged latency in the left median and both peroneal nerves with reduced amplitudes distally with normal conduction velocities (CV). The right median nerve was in- elicitable. $\mathrm{F}$ wave latency is prolonged in left median nerve with rest being normal. Sensory nerve conductions show absent SNAP in right median with normal peak latency and conduction velocity in both ulnar and sural nerves

NCS 2: The motor nerve conduction studies showed prolonged distal latencies in both ulnar, tibial and peroneal nerves with reduced amplitudes distally and conduction block with more than $50 \%$ reduction in amplitude on proximal stimulation in right ulnar nerve with reduced conduction velocities. $\mathrm{F}$ wave latencies are prolonged in bilateral tibial and peroneal nerves with absent $\mathrm{F}$ wave latency in the bilateral median and right ulnar nerves. Sensory nerve conductions being non-recordable in all tested nerves

NCS nerve conduction studies, CV conduction velocity, NR not recordable 
infiltrates of inflammatory cells in more than half individuals [3, 4]. Contrast enhancement and root enlargement on MRI attribute to CIDP [5]. Newer MRI techniques like modified diffusion-weighted MRI are showing a promising role in CIDP [6]. It has a broad spectrum of clinical presentations, which include sensory-motor, symmetrical polyneuropathy, predominantly distal features, exclusively sensory signs and symptoms, asymmetrical presentation, predominant cranial nerve involvement and associated CNS demyelination [7]. It may be either progressive or recurrent relapsing in nature. Predominant or isolated cranial nerve involvement at the time of initial presentation is uncommon. It can occur before the onset of limb weakness and fatiguability. The duration between cranial neuropathy and limb involvement is variable. More commonly reported with cranial nerves are III, IV and VI and VII nerves [8]. Involvement of cranial nerves IX and $\mathrm{X}$ are very rare. Only one case report has been reported from Japan by Hiroko Teramoto et al. in a 69-year-old female presented with dysphagia with quadriparesis showing dramatic improvement with intravenous immunoglobulin [9]. Rarely hypoglossal nerve involvement is also seen in CIDP [10].

Treatment is the same as that of typical CIDP [11]. Corticosteroids are the mainstay of therapy with usual regimen of 60 to $80 \mathrm{mg}$ of prednisone daily, tapered over months to the lowest effective dose, typically 25 to $40 \mathrm{mg}$. Improvement occurs as earliest as 2 months to maximal at 6 months. Age and clinical variables also help in treatment prognostication. Older adults have lesser recovery compared to young and adolescent group [12]. Proximal weakness tends to have better prognosis but higher remission rate compared to distal phenotype [13]. Due to dependency and side effects with corticosteroids usage, alternative modalities like intravenous immunoglobulin and plasma exchange are preferred. Intravenous infusion of gamma globulin $(2 \mathrm{~g} / \mathrm{kg}$ in divided infusions over 2 to 5 days) had shown improvement in more than $50 \%$ individuals. Plasma exchange which is administered twice weekly for 3 weeks had a beneficial effect on both neurologic disability and nerve conduction. The impact of plasma exchanges in most patients subsides in 10 to 21 days [14]. If the above measures prove unsatisfactory, immunosuppressants like cyclophosphamide, mycophenolate, etanercept or rituximab, can be added which are showing promising results [15-17]. Studies have shown, rituximab showcasing a significant treatment modality if shown failure response to steroids and IVIg in CIDP individuals like in our study, who initially demonstrated inadequate response to both steroids and intravenous immunoglobulin but have shown significant improvement with rituximab.

\section{Conclusion}

Isolated cranial nerve involvement presenting as CIDP is a rare entity. Intravenous immunoglobulin and newer immunosuppressants like CD-20 monoclonal antibodies like rituximab have a significant role in the treatment of CIDP apart from corticosteroids.

\section{Abbreviations \\ CIDP: Chronic inflammatory demyelinating polyradiculoneuropathy; CSF: Cerebrospinal fluid; CT: Computed tomography; IVlg: Intravenous Immunoglobulin; LP: Lumbar puncture; MMSE: Mini-Mental Status Examination; MRI: Magnetic resonance imaging; NCS: Nerve conduction studies; TB-PCR: Mycobacterium tuberculosis - polymerase chain reaction test}

\section{Acknowledgements}

Nil

\section{Authors' contributions}

MK has contributed to concept, design, analysing and interpreting the data; drafting and revision of the article and approving the final version to be published. BR: analysing and interpreting the data; drafting and revision of the article and approving the final version to be published.

\section{Funding}

Nil sources of funding.

\section{Availability of data and materials Not applicable.}

\section{Ethics approval and consent to participate}

Obtained. Approved by PSG Institute of Medical Sciences \&Research Institutional Human Ethics Committee Recognized by The Strategic Initiative for Developing Capacity in Ethic at Review (SIDCER). Project No. 18/295.

\section{Consent for publication}

Obtained.

\section{Competing interests}

The authors declare that they have no competing interests.

Received: 24 September 2019 Accepted: 19 November 2019 Published online: 04 December 2019

\section{References}

1. Gorson KC, Katz J. Chronic inflammatory demyelinating polyneuropathy. Neurol Clin. 2013;31(2):511-32.

2. Kerasnoudis A, Pitarokoili K, Gold R, Yoon MS. The application of clinical, electrophysiological and nerve ultrasound parameters in distinguishing acute-onset chronic from acute inflammatory demyelinating polyneuropathy. Eur Neurol Rev. 2015;10(1):85-9.

3. Antoine JC, Azulay JP, Bouche P, Créange A, Fournier E, Gallouedec G, et al. Recommendations on diagnostic strategies for chronic inflammatory demyelinating polyradiculoneuropathy. Postgrad Med J. 2008:84(993):378-81.

4. Research criteria for diagnosis of chronic inflammatory demyelinating polyneuropathy (CIDP). Report from an Ad Hoc Subcommittee of the American Academy of Neurology AIDS Task Force. Neurology. 1991;41(5): 617-8.

5. Duggins AJ, McLeod JG, Pollard JD, Davies L, Yang F, Thompson EO, et al. Spinal root and plexus hypertrophy in chronic inflammatory demyelinating polyneuropathy. Brain. 1999;122(Pt 7):1383-90.

6. Tsuchiya K, Honya K, Yoshida M, Nitatori T. Demonstration of spinal cord and nerve root abnormalities by diffusion neurography. J Comput Assist Tomogr. 2008;32(2):286-90.

7. Mathey EK, Park SB, Hughes RAC, Pollard JD, Armati PJ, Barnett MH, et al. Chronic inflammatory demyelinating polyradiculoneuropathy: from pathology to phenotype. J Neurol Neurosurg Psychiatry. 2015;86(9):973-85.

8. Spataro R, La Bella V. Long-lasting cranial nerve III palsy as a presenting feature of chronic inflammatory demyelinating polyneuropathy. Case Rep Med. 2015;2015:769429. 
9. Teramoto H, Morita A, Hara M, Ninomiya S, Shigihara S, Kusunoki S, et al. Relapse with dysphagia in a case of chronic inflammatory demyelinating polyradiculoneuropathy. Intern Med. 2015;54(14):1791-3.

10. Yamashiro K, Okuma Y, Fujishima K, Goto K, Mizuno Y. Bilateral hypoglossal nerve involvement in chronic inflammatory demyelinating polyneuropathy. Eur Neurol. 2004;51(1):45-6.

11. Van Den Bergh PYK, Hadden RDM, Bouche P, Cornblath DR, Hahn A, Illa I, et al. European federation of neurological societies/peripheral nerve society guideline on management of chronic inflammatory demyelinating polyradiculoneuropathy: Report of a joint task force of the European federation of neurological societies and the periphery. Journal of the Peripheral Nervous System. 2010;17(3):356-63.

12. Hattori N, Misu K, Koike H, Ichimura M, Nagamatsu M, Hirayama M, et al. Age of onset influences clinical features of chronic inflammatory demyelinating polyneuropathy. J Neurol Sci. 2001;184(1):57-63.

13. Mygland Å, Monstad P, Vedeler C. Onset and course of chronic inflammatory demyelinating polyneuropathy. Muscle Nerve. 2005;31(5):589-93.

14. Vallat JM, Sommer C, Magy L. Chronic inflammatory demyelinating polyradiculoneuropathy: diagnostic and therapeutic challenges for a treatable condition. Lancet Neurol. 2010;9(4):402-12.

15. Gorson KC, Amato AA, Ropper AH. Efficacy of mycophenolate mofetil in patients with chronic immune demyelinating polyneuropathy. Neurology. 2004;63(4):715-7.

16. Chin RL, Sherman WH, Sander HW, Hays AP, Latov N. Etanercept (Enbre ${ }^{\oplus}$ ) therapy for chronic inflammatory demyelinating polyneuropathy. J Neurol Sci. 2003;210(1-2):19-21.

17. Briani C, Zara G, Zambello R, Trentin L, Rana M, Zaja F. Rituximab-responsive CIDP [1]. Eur J Neurol. 2004;11(11):788.

\section{Publisher's Note}

Springer Nature remains neutral with regard to jurisdictional claims in published maps and institutional affiliations.

\section{Submit your manuscript to a SpringerOpen ${ }^{\circ}$ journal and benefit from:}

- Convenient online submission

- Rigorous peer review

- Open access: articles freely available online

High visibility within the field

- Retaining the copyright to your article

Submit your next manuscript at $\boldsymbol{\nabla}$ springeropen.com 